\title{
Chronic intermittent hypobaric hypoxia protects the heart against ischemia/reperfusion injury through upregulation of antioxidant enzymes in adult guinea pigs
}

\author{
Hui-cai GUO, Zhe ZHANG, Li-nan ZHANG, Chen XIONG, Chen FENG, Qian LIU, Xu LIU, Xiao-lu SHI, Yong-li WANG* \\ Department of Pharmacology, Hebei Medical University, Shijiazhuang 050017, China
}

\begin{abstract}
Aim: To investigate the protection and the anti-oxidative mechanism afforded by chronic intermittent hypobaric hypoxia (CIHH) against ischemia/reperfusion (I/R) injury in guinea pig hearts.

Methods: Adult male guinea pigs were exposed to $\mathrm{ClHH}$ by mimicking a $5000 \mathrm{~m}$ high altitude $\left(p_{\mathrm{B}}=404 \mathrm{mmHg}, p_{02}=84 \mathrm{mmHg}\right)$ in a hypobaric chamber for $6 \mathrm{~h} /$ day for 28 days. Langendorff-perfused isolated guinea pig hearts were used to measure variables of left ventricular function during baseline perfusion, ischemia and the reperfusion period. The activity and protein expression of antioxidant enzymes in the left myocardium were evaluated using biochemical methods and Western blotting, respectively. Intracellular reactive oxygen species (ROS) were assessed using ROS-sensitive fluorescence.

Results: After $30 \mathrm{~min}$ of global no-flow ischemia followed by $60 \mathrm{~min}$ of reperfusion, myocardial function had better recovery rates in $\mathrm{CIHH}$ guinea pig hearts than in control hearts. The activity and protein expression of superoxide dismutase (SOD) and catalase (CAT) were significantly increased in the myocardium of $\mathrm{CIHH}$ guinea pigs. Pretreatment of control hearts with an antioxidant mixture containing SOD and CAT exerted cardioprotective effects similar to $\mathrm{CIHH}$. The irreversible CAT inhibitor aminotriazole (ATZ) abolished the cardioprotection of $\mathrm{ClHH}$. Cardiac contractile dysfunction and oxidative stress induced by exogenous hydrogen peroxide $\left(\mathrm{H}_{2} \mathrm{O}_{2}\right)$ were attenuated by $\mathrm{ClHH}$ and CAT.
\end{abstract}

Conclusions: These data suggest that $\mathrm{CIHH}$ protects the heart against I/R injury through upregulation of antioxidant enzymes in guinea pig.

Keywords: chronic intermittent hypobaric hypoxia; cardioprotection; antioxidant enzymes; ischemia/reperfusion; guinea pig

Acta Pharmacologica Sinica (2009) 30: 947-955; doi: 10.1038/aps.2009.57; published online 22 June 2009

\section{Introduction}

Increasing evidence has shown that chronic intermittent hypobaric hypoxia $(\mathrm{CIHH})$ effectively protects the heart against ischemia/reperfusion (I/R) or hypoxia/reoxygenation injury $^{[1,2]}$. The protective effects promote recovery of cardiac contractile function from $\mathrm{I} / \mathrm{R}$, limiting cardiac infarct and arrhythmia induced by $I / R^{[3-5]}$. Several potential factors have been proposed to be involved in the protective mechanism afforded by $\mathrm{CIHH}$, including regulation of myocardial heat shock protein expression, amelioration of coronary circulation and angiogenesis, activation of protein kinase $\mathrm{C}$ and involvement of $K_{\text {ATP }}$ channels ${ }^{[6-9]}$. However, the precise mechanisms

\footnotetext{
* To whom correspondence should be addressed. E-mail wangyl@hebmu.edu.cn

Received 2009-01-06 Accepted 2009-04-14
}

underlying the protective effects of $\mathrm{CIHH}$ on ischemic hearts are far from clear.

It is well known that oxidative stress and oxygen-derived free radicals [primarily reactive oxygen species (ROS)] contribute to $I / R$ injury ${ }^{[10,11]}$. Many proteins that have key roles in the homeostasis of cardiomyocytes, such as the $\mathrm{Na}^{+} / \mathrm{Ca}^{2+}$ exchanger and the sodium pump, are modified during massive ROS release ${ }^{[12,13]}$. Intercellular antioxidant enzymes, which can eliminate the oxygen-derived free radicals, include glutathione peroxidase (GPX), catalase (CAT) and superoxide dismutase (SOD). SOD includes a cytosolic dimeric $\mathrm{Cu}$ / ZnSOD (SOD-1) and a mitochondrial tetrameric MnSOD (SOD-2) ${ }^{[14]}$ enzyme, which contribute to the first line of antioxidant defenses by catalyzing the conversion of $\mathrm{O}_{2}^{-}$into hydrogen peroxide $\left(\mathrm{H}_{2} \mathrm{O}_{2}\right)$. Both GPX and CAT belong to the secondary line of antioxidant defenses by catalyzing the con- 
version of $\mathrm{H}_{2} \mathrm{O}_{2}$ to $\mathrm{H}_{2} \mathrm{O}$. Thus, it is generally considered that manipulations that enhance the antioxidant activity in heart tissue may be useful in preventing I/R injury. Previous findings have shown that renal SOD levels in rats were increased during hypoxic preconditioning ${ }^{[15]}$. Hyperbaric oxygenation pretreatment can induce CAT and reduce infarct size in the ischemic rat myocardium ${ }^{[16]}$. Previous studies on the cardioprotection of $\mathrm{CIHH}$ have shown that antioxidant activity increases, suggesting a role for antioxidation in the cardioprotective mechanism of $\mathrm{CIHH}^{[4,17,18]}$. It was reported, however, that antioxidant enzymes in rats submitted to $\mathrm{CIHH}(7000 \mathrm{~m}$ altitude, $8 \mathrm{~h} /$ day and 5 days/week for 24-30 days) were not significantly altered ${ }^{[19]}$. Whether or not antioxidation contributed to the cardioprotection of $\mathrm{CIHH}$ as well as the details of the underlying mechanisms are yet to be elucidated.

The cardioprotective nature of $\mathrm{CIHH}$ is affected by many factors, such as the level, duration and protocol of hypoxia ${ }^{[2]}$. It also depends on resistance to hypoxia, which varies between animals. For example, guinea pigs are relatively resistant to hypoxia ${ }^{[20,21]}$. To date, using $\mathrm{CIHH}$ as a cardioprotective measure has been approved in some animals, such as rats and $\operatorname{dogs}^{[5]}$; however, it has yet to be approved for use in guinea pigs.

The aim of the present study was to evaluate (i) whether $\mathrm{CIHH}$ could protect the hearts of adult guinea pigs against $I / R$ injury by using recovery of ventricular function as an end point, and (ii) whether antioxidation is involved in the cardioprotection afforded by $\mathrm{CIHH}$.

\section{Materials and methods}

\section{Animal ClHH treatment}

Adult male guinea pigs ( $250 \pm 20 \mathrm{~g}, n=134)$ were provided by the Experimental Animal Center of Hebei Medical University (Shijiazhuang, China). All animals were treated in accordance with the Guide for Care and Use of Laboratory Animals published by the US National Institutes of Health, and divided into non-CIHH and $\mathrm{CIHH}$ groups. Guinea pigs submitted to $\mathrm{CIHH}$ were exposed to intermittent high-altitude hypoxic conditions of $5000 \mathrm{~m}\left(p_{\mathrm{B}}=404 \mathrm{mmHg}, p_{\mathrm{O} 2}=84 \mathrm{mmHg}\right)$ in a hypobaric chamber for $6 \mathrm{~h} /$ day for 28 days, and non-CIHH guinea pigs were kept in the same environment without hypoxic exposure as a control. All animals were used for further experiments on the day following the pretreatment described above. Both groups of guinea pigs were raised at room temperature $\left(20-24^{\circ} \mathrm{C}\right)$ with a natural light-dark cycle $(12 \mathrm{~h}: 12 \mathrm{~h})$ and had free access to water and food throughout pretreatment.

\section{Perfusion of the isolated hearts and measurement of cardiac function}

Both $\mathrm{CIHH}$ and non-CIHH guinea pigs were anesthetized with sodium pentobarbital [60 mg/ kg, intraperitoneally (ip)] as previously described $^{[22]}$. The heart was quickly excised, mounted on a Langendorff apparatus and perfused with KrebsHenseleit buffer (K-H buffer) gassed with $95 \% \mathrm{O}_{2}-5 \% \mathrm{CO}_{2}$ and kept at $37^{\circ} \mathrm{C}$ at a constant pressure of $80 \mathrm{mmHg}$. Composition of the K-H buffer ( $\mathrm{pH} 7.4$ ) was (in $\mathrm{mmol} / \mathrm{L}$ ): $\mathrm{NaCl} 118.0, \mathrm{KCl}$ 4.7, $\mathrm{CaCl}_{2} 2.5, \mathrm{MgSO}_{4} 1.2, \mathrm{NaHCO}_{3} 25.0, \mathrm{KH}_{2} \mathrm{PO}_{4} 1.2$ and glucose 11.0. A water-filled latex balloon connected to a pressure transducer (Gould P23Db) was introduced into the left ventricle via the mitral valve to record isovolumic left ventricular pressure. The balloon volume was adjusted to achieve a stable left ventricular end-diastolic pressure (LVEDP) of 5-10 $\mathrm{mmHg}$ during the initial equilibration. Coronary flow rate $(\mathrm{CF})$ was obtained by collecting the coronary effluent for $1 \mathrm{~min}$. Heart rate (HR), left ventricular peak systolic pressure (LVPSP) and peak rate of pressure that developed $\left( \pm \mathrm{d} p / \mathrm{d} t_{\max }\right)$ were monitored using a PowerLab system (AD Instrument Ltd, Castle Hill, Australia) before and after I/R. Pressure-rate product (PRP) and left ventricular developed pressure (LVDP) were calculated as LVDP $=$ LVPSP - LVEDP and PRP $=H R \times L V D P$, respectively.

\section{Experimental protocol and groups}

Six hearts from each group (non-CIHH and $\mathrm{CIHH}$ ) used for the analysis of myocardial hypertrophy were rapidly excised and washed in saline. Incisions were made into the right ventricle and left ventricle through the interventricular septum. All parts were weighed and the corresponding ratios were calculated.

Seventy guinea pigs were divided into five groups: (1) non-CIHH (CON), (2) CON+antioxidant enzyme, (3) $\mathrm{CON}+$ aminotriazole (ATZ), (4) $\mathrm{CIHH}$ only, and (5) $\mathrm{CIHH}+$ ATZ. To detect the effect of antioxidant on the cardioprotection of $\mathrm{CIHH}, 35$ hearts ( $n=7$ in each group) were subjected to I/R injury using a protocol of 20-min baseline perfusion, 30 min no-flow global ischemia, followed by a 60 min reperfusion. Hearts in the $\mathrm{CON}+$ antioxidant enzyme $(\mathrm{CON}+\mathrm{SOD}+\mathrm{CAT})$ group were perfused with an antioxidant mixture containing SOD $(100 \mathrm{U} / \mathrm{mL})^{[23]}$ and CAT $(120$ $\mathrm{U} / \mathrm{mL})^{[23]}$ for $10 \mathrm{~min}$ before ischemia until the end of I/R. To examine whether the beneficial effects of $\mathrm{CIHH}$ on I/R injury are a result of its increased antioxidant activity, 35 hearts $(n=7$ in each group) were subjected to a protocol of $20 \mathrm{~min}$ baseline perfusion and $30 \mathrm{~min} \mathrm{H}_{2} \mathrm{O}_{2}(300 \mu \mathrm{mol} / \mathrm{L} \text {, a potent oxidant })^{[32]}$ perfusion. Hearts in $\mathrm{CON}+$ antioxidant enzyme $(\mathrm{CON}+\mathrm{CAT})$ group were perfused with CAT $(120 \mathrm{U} / \mathrm{mL})$ for $10 \mathrm{~min}$ before $\mathrm{H}_{2} \mathrm{O}_{2}$ treatment until the end of the protocol. In all CON+ATZ and $\mathrm{CIHH}+\mathrm{ATZ}$ groups, ATZ $(1.0 \mathrm{~g} / \mathrm{kg})^{[29,42]}$ was administered to the guinea pig intraperitoneally $1 \mathrm{~h}$ before heart isolation.

To observe the effects of $\mathrm{CIHH}$ on antioxidant enzyme activity and protein level in guinea pig myocardial tissue before and after I/R, 24 hearts were divided into four groups $(n=6$ in each group): (1) non-CIHH baseline, (2) non-CIHH I/R, (3) CIHH baseline, and (4) CIHH I/R. All I/R hearts were subjected to a protocol of $20 \mathrm{~min}$ baseline perfusion, $30 \mathrm{~min}$ noflow global ischemia, followed by a $60 \mathrm{~min}$ reperfusion. All baseline hearts were subjected to $20 \mathrm{~min}$ baseline perfusion. The hearts were then frozen in liquid nitrogen and stored at $-80^{\circ} \mathrm{C}$ 
Measurement of antioxidant enzyme activity and lipid superoxide level

The myocardium was rinsed and then homogenized in buffer composed of (in mmol/L) ${ }^{[24]}$ : Tris- $\mathrm{HCl} 10, \mathrm{NaCl} 137, \mathrm{Na}_{2} \mathrm{E}-$ DTA 1, dithiotreitol (DTT) 0.5, and sucrose 250 at pH 7.4 using a homogenizer (T 18 basic Ultra-Turrax ${ }^{\circledR}$; Mandel Scientific Company Inc, Guelph, Canada). The homogenate was centrifuged at $1000 \times g$ for $15 \mathrm{~min}$ at $4{ }^{\circ} \mathrm{C}$. The supernatants were used for biochemical assay and Western blot analysis. The activity of total SOD, SOD-1, SOD-2, CAT and GPX and the content of malondialdehyde (MDA) were used as indices of antioxidant capacity and lipid superoxide level, respectively. Measurements were made using commercial kits (Jiancheng Bioengineering Institute, Nanjing, China) with a spectrophotometer (Perkin- Elmer, Norwalk, CT, USA). Total SOD activity was determined by inhibition of pyrogallol antioxidation. To determine SOD-2 activity, the assay was repeated in the presence of potassium cyanide $(1 \mathrm{mmol} / \mathrm{L})$, which inhibits the activity of SOD-1. The activity of SOD-1 was calculated as the difference between the total SOD activity (without potassium cyanide) and the SOD-2 activity (with potassium cyanide). A unit of the enzyme is generally defined as the amount of enzyme that inhibits the reaction by $50 \%{ }^{[17]}$. MDA was determined by a variation of the thiobarbituric acid method. The activity of CAT and GPX was measured by the method described by Zang et al ${ }^{[25]}$. Protein concentration was measured using the bicinchoninic acid method (Pierce, Rockford, USA) with bovine serum albumin as a standard.

\section{Measurement of antioxidant enzyme protein level}

The protein of supernatants was separated using SDS-PAGE on $12 \%$ acrylamide gels. They were then transferred onto polyvinylidene fluoride (PVDF) membranes and blocked with 5\% nonfat dry milk in Tris Buffered Saline Tween-20 (TBST) buffer (50 Tris- $\mathrm{HCl}, 150 \mathrm{mmol} / \mathrm{L} \mathrm{NaCl}, 0.1 \%$ Tween, $\mathrm{pH} 7.4$ ) for $1 \mathrm{~h}$ at room temperature. Membranes were then incubated with the polyclonal IgG for SOD-1, SOD-2, and CAT (dilution 1:200) overnight at $4{ }^{\circ} \mathrm{C}$, washed with TBST three times for 10 min each, and then incubated with horseradish peroxidaseconjugated secondary antibody $(1: 2000)$ for $1 \mathrm{~h}$ at $37^{\circ} \mathrm{C}$. After washing, blots were detected using an enhanced chemiluminescence plus system (ZhongShan Bioengineering Institute, Beijing, China). Quantification of Western blot signals was performed using densitometric measurements. The data were normalized to the ratios of $\beta$-actin (dilution 1:800) detected on the same blot to control for possible variations in protein loading.

\section{Measurement of ROS in isolated ventricular myocytes}

Myocytes were enzymatically isolated from the left ventricles of non-CIHH or CIHH guinea pigs as previously described ${ }^{[26]}$. Briefly, guinea pigs were anesthetized with sodium pentobarbitone solution $(60 \mathrm{mg} / \mathrm{kg}$, ip). The heart was quickly excised and perfused in a retrograde fashion with oxygenated $\mathrm{Ca}^{2+}$ -

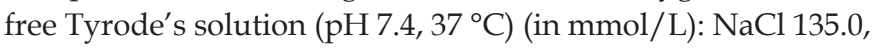
$\mathrm{KCl} 5.4, \mathrm{MgCl}_{2}$ 1.0, $\mathrm{NaH}_{2} \mathrm{PO}_{4}$ 0.33, HEPES 5.0 and glucose 10.0, and gassed with pure $\mathrm{O}_{2}$ for $5 \mathrm{~min}$. The perfusion solution was then switched to $\mathrm{Ca}^{2+}$-free Tyrode's solution containing $0.4 \mathrm{mg} / \mathrm{mL}$ collagenase II (Worthington Biochemical Co, Lakewood, NJ, USA) for $15 \mathrm{~min}$. The left ventricle was removed and agitated mechanically in high- $\mathrm{K}^{+}$Kraft-Bruhe (KB) solution to obtain single ventricular myocytes, which were used within $6 \mathrm{~h}$ after isolation. The composition of the high- $\mathrm{K}^{+} \mathrm{KB}$ solution was (in mmol/L): $\mathrm{KOH} 80, \mathrm{KCl} 40, \mathrm{MgSO}_{4} 3, \mathrm{KH}_{2} \mathrm{PO}_{4}$ 25, glutamic acid 50, taurine 20, HEPES 10, EGTA 1 and glucose 10 , at $\mathrm{pH} 7.2$.

Intracellular oxidative stress was monitored by using the probe 29, 79-dichlorofluorescin diacetate (DCFH-DA; Molecular Probes, USA). Cells were loaded with $10 \mu \mathrm{mol} / \mathrm{L}$ DCFH-DA for $30 \mathrm{~min}$ at room temperature in the dark. After loading, cells were washed twice and maintained in Tyrode's solution $\left(\mathrm{Ca}^{2+}\right.$-free Tyrode's solution $\left.+\mathrm{CaCl}_{2} 1.8 \mathrm{mmol} / \mathrm{L}\right)$ until the assay was performed. For confocal imaging, a Leica (Wetzlar, Germany) DM-IRBE inverted microscope fitted with a TCS-SP2 scan head was used. Excitation of DCFH-DA was achieved with a $488 \mathrm{~nm}$ argon ion laser line, and emissions were collected at 500-565 nm. The fluorescent intensity (FI) was measured before $\left(\mathrm{FI}_{0}\right)$ and after $(\mathrm{FI})$ adding $\mathrm{H}_{2} \mathrm{O}_{2}$ into the Tyrode's solution. The change of ROS was calculated using the ratio of $\left(\mathrm{FI}^{-} \mathrm{FI}_{0}\right) / \mathrm{FI}_{0}$.

Myocytes were divided into five groups ( $n=18$ in each group, from 3-4 different hearts): (1) non-CIHH (CON1), (2) CON1+CAT, (3) CON1+ATZ, (4) CIHH1, and (5) CIHH1+ATZ group. In the present study, we used $10 \mathrm{~min}$ baseline perfusion and a $10 \mathrm{~min} \mathrm{H}_{2} \mathrm{O}_{2}(1 \mathrm{mmol} / \mathrm{L})$ treatment protocol. The myocytes in the CON1+CAT group were treated with CAT $(100 \mathrm{U} / \mathrm{mL})$ for $5 \mathrm{~min}$ before and $10 \mathrm{~min}$ during $\mathrm{H}_{2} \mathrm{O}_{2}$ treatment. Aminotriazole was administered intraperitoneally to the guinea pigs at $1 \mathrm{~h}$ before isolation of the hearts from the CON1+ATZ and CIHH1+ATZ groups.

\section{Reagents}

The SOD, CAT, ATZ, and $\mathrm{H}_{2} \mathrm{O}_{2}$ were purchased from Sigma Chemical Company (St Louis, MO). Antibodies against SOD-1, SOD-2, CAT, and $\beta$-actin (Santa Cruz Biotechnological Co Santa Cruz, CA) were used.

\section{Statistical analysis}

All data are expressed as mean \pm SEM. Statistical analysis was carried out using a one-way ANOVA or Student's $t$ tests when appropriate. Differences were considered significant at $P<0.05$.

\section{Results}

\section{Effects of $\mathrm{ClHH}$ on body weight and heart weight}

The body weight of guinea pigs in the $\mathrm{CIHH}$ groups had no significant change compared with the non-CIHH group (Table 1). No differences were found in the ratio of heart weight to body weight, the ratio of left ventricular plus interventricular septum weight to body weight, the ratio of right ventricular weight to left ventricular plus interventricular septum weight or the ratio of right ventricular weight to body weight between 
Table 1. Effects of $\mathrm{ClHH}$ on body weight and heart weight of guinea pigs. $n=6$. Values are means \pm SEM.

\begin{tabular}{lccccc}
\hline Group & BW (g) & HW/BW (g/kg) & $($ LVW+ISW)/BW (g/kg) & RVW/(LVW+ISW) (g/g) & RVW/BW (g/kg) \\
\hline non-ClHH & $365.4 \pm 5.3$ & $3.60 \pm 0.16$ & $2.57 \pm 0.06$ & $0.25 \pm 0.01$ & $0.64 \pm 0.05$ \\
$\mathrm{ClHH}$ & $355.6 \pm 5.8$ & $3.65 \pm 0.14$ & $2.51 \pm 0.09$ & $0.21 \pm 0.01$ & $0.71 \pm 0.04$ \\
\hline
\end{tabular}

BW, body weight; HW/BW, ratio of heart weight to body weight; (LVW+ISW)/BW, ratio of left ventricular plus inter-ventricular septum weight to body weight; RVW/(LVW+ISW), ratio of right ventricular weight to left ventricular plus inter-ventricular septum weight; RVW/BW, ratio of right ventricular weight to body weight. non- $\mathrm{ClHH}$, control group; $\mathrm{ClHH}$, chronic intermittent hypobaric hypoxia group.

the $\mathrm{CIHH}$ groups and the non- $\mathrm{CIHH}$ group. These findings indicate that $\mathrm{CIHH}$ in this experimental paradigm may not result in heart hypertrophy in guinea pigs.

\section{Effects of $\mathrm{ClHH}$ on recovery of coronary flow and left ventricular function after $\mathrm{I} / \mathrm{R}$}

All cardiac function parameters in each group were altered after I/ R $(P<0.05$ or 0.01$)$, with the exception of HR (Table 2). Among them, CF, LVPSP, $\pm \mathrm{d} p / \mathrm{d} t_{\max }$ and PRP were greatly reduced, whereas LVEDP was significantly increased. However, I/R-induced harmful changes of these parameters, with the exception of LVPSP, were modestly improved by $\mathrm{CIHH}$ adaptation $(P<0.05$ or 0.01$)$. A similar improvement was observed in non-CIHH hearts treated with SOD+CAT $(P<0.05$ or 0.01$)$. Moreover, treatment with ATZ $(1.0 \mathrm{~g} / \mathrm{kg})$ completely abolished the improvement of $\mathrm{CIHH}$ on cardiac function impaired by I/ $(P<0.01)$, suggesting that the beneficial effects of $\mathrm{CIHH}$ on cardiac performance in hearts that underwent I/R may be related to its antioxidant capacity. Pretreatment with $\mathrm{CIHH}$ did not change cardiac function parameters before $I / R$, except for $\mathrm{CF}$, which was increased by $\mathrm{CIHH}$ and not abolished by ATZ.

\section{Effects of $\mathrm{CIHH}$ on antioxidant enzymes and MDA in the left ventricle}

The biochemical experiment demonstrated that the baseline activity of total SOD, SOD-2, and CAT in CIHH hearts was higher than those in non-CIHH hearts (Figure 1, $P<0.01$ ); however, SOD-1, and GPX activity and MDA content did not significantly change. After I/R, total SOD, SOD-1, SOD-2, and CAT activity decreased and MDA content significantly increased in non-CIHH and CIHH hearts $(P<0.01)$, whereas the activity of total SOD, SOD-2, and CAT in CIHH hearts was still higher than those in non-CIHH hearts $(P<0.01)$. Moreover, the content of MDA was lower in CIHH hearts than in non$\mathrm{CIHH}$ hearts $(P<0.01)$. Western blot analysis demonstrated that the baseline expression of SOD-2 ( $25 \mathrm{kDa}$ band) and CAT

Table 2. Effects of $\mathrm{CIHH}$ on hemodynamic parameters in guinea pigs suffered from ischemia and reperfusion. $n=7$. Values are means $\pm \mathrm{SEM}$. ${ }^{\mathrm{b}} P<0.05$, ${ }^{\mathrm{c}} P<0.01$ vs corresponding baseline perfusion; ${ }^{\mathrm{e}} \mathrm{P}<0.05,{ }^{\mathrm{f}} \mathrm{P}<0.01$ vs corresponding of $\mathrm{CON}$; ${ }^{\mathrm{h}} \mathrm{P}<0.05,{ }^{\mathrm{i}} P<0.01$ vs corresponding of $\mathrm{ClHH}$.

\begin{tabular}{|c|c|c|c|c|c|}
\hline & CON & $\mathrm{CON}+\mathrm{SOD}+\mathrm{CAT}$ & $\mathrm{CON}+\mathrm{ATZ}$ & $\mathrm{ClHH}$ & $\mathrm{ClHH}+\mathrm{ATZ}$ \\
\hline \multicolumn{6}{|l|}{ Baseline } \\
\hline LVPSP (mmHg) & $97.8 \pm 2.4$ & $92.5 \pm 3.9$ & $102.6 \pm 5.9$ & $97.6 \pm 7.9$ & $94.8 \pm 6.3$ \\
\hline LVEDP (mmHg) & $8.2 \pm 1.0$ & $8.2 \pm 0.7$ & $8.2 \pm 2.0$ & $6.6 \pm 1.3$ & $7.4 \pm 1.0$ \\
\hline HR (beat/min) & $244 \pm 16$ & $256 \pm 14$ & $250 \pm 19$ & $256 \pm 19$ & $262 \pm 17$ \\
\hline $\operatorname{PRP}\left(10^{3} \mathrm{mmHg} / \mathrm{min}\right)$ & $21.2 \pm 1.6$ & $21.4 \pm 1.8$ & $23.7 \pm 2.2$ & $23.3 \pm 3.5$ & $23.1 \pm 2.4$ \\
\hline \multicolumn{6}{|l|}{ Reperfusion } \\
\hline $\mathrm{CF}(\mathrm{mL} / \mathrm{min})$ & $7.9 \pm 0.6^{c}$ & $12.8 \pm 0.8^{\mathrm{cf}}$ & $7.3 \pm 0.7^{\circ}$ & $15.6 \pm 1.4^{\text {cf }}$ & $9.9 \pm 0.7^{\mathrm{ci}}$ \\
\hline LVPSP (mmHg) & $79.8 \pm 5.0^{b}$ & $71.1 \pm 2.3^{b}$ & $82 \pm 5.4^{b}$ & $75.2 \pm 6.3^{b}$ & $77.7 \pm 3.0^{b}$ \\
\hline $\operatorname{PRP}\left(10^{3} \mathrm{mmHg} / \mathrm{min}\right)$ & $7.2 \pm 0.8^{c}$ & $11.8 \pm 0.7^{\text {cf }}$ & $6.1 \pm 0.9^{c}$ & $12.9 \pm 1.0^{\mathrm{cf}}$ & $8.9 \pm 0.6^{\mathrm{ch}}$ \\
\hline
\end{tabular}

CF, coronary flow; LVPSP, left ventricular peak systolic pressure; LVEDP, left ventricular end-diastolic pressure; HR, heart rate; $\pm d p / d t_{\text {max }}$, peak rate of pressure developed; PRP, pressure-rate product. CON, control hearts; SOD, superoxide dismutase; CAT, catalase; ATZ, aminotriazole; CON+SOD+CAT, antioxidant mixture containing SOD and CAT was infused into the perfusion stream in control hearts; $\mathrm{CIHH}$, chronic intermittent hypobaric hypoxia hearts; CON+ATZ, control guinea pigs pretreated with ATZ (1.0 g/Kg). ClHH+ATZ, ClHH guinea pigs pretreated with ATZ. 

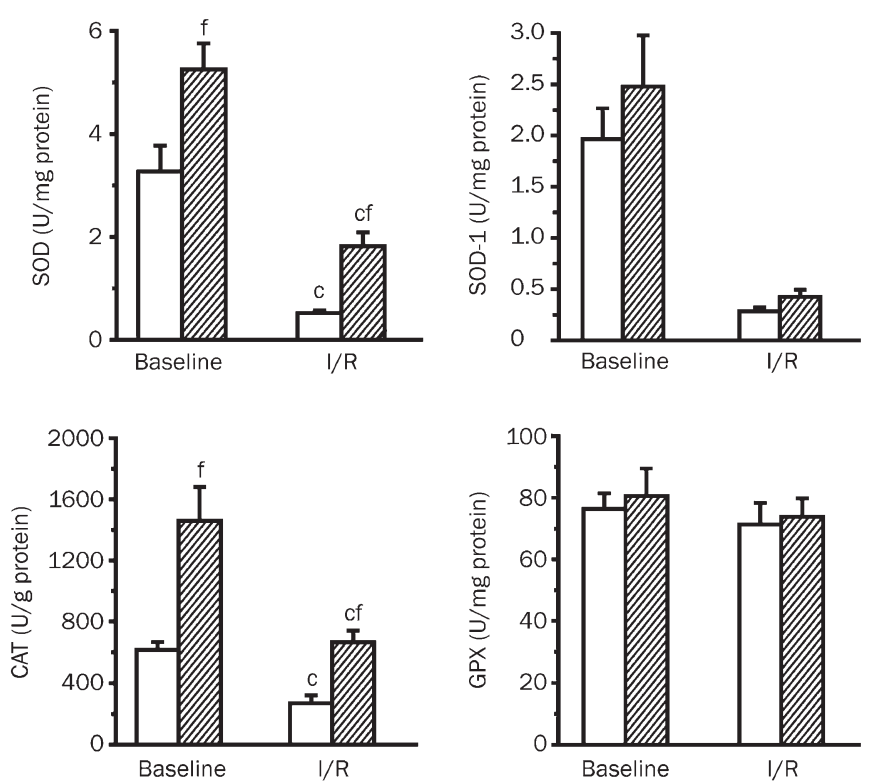

(64 kDa band) protein was higher in $\mathrm{CIHH}$ hearts than in non$\mathrm{CIHH}$ hearts $(P<0.05)$ (Figure 2$)$. However, the expression of SOD-1 protein did not change. The protein expression of SOD-1, SOD-2, and CAT did not significantly change after I/R in the non-CIHH and $\mathrm{CIHH}$ hearts, whereas the expression of SOD-2 and CAT in $\mathrm{CIHH}$ hearts was still higher than those in non-CIHH hearts $(P<0.01)$. These results indicate that $\mathrm{CIHH}$ increases the activity of SOD-2 and CAT by upregulating their respective protein expression.

\section{Effects of $\mathrm{ClHH}$ on $\mathrm{H}_{2} \mathrm{O}_{2}$-induced heart contractile dysfunction}

Data shown in Table 3 indicated that $\mathrm{H}_{2} \mathrm{O}_{2}$ perfusion for 30 min, like I/R, induced a similar alteration in all cardiac funtion parameters except for HR in all groups. Significant
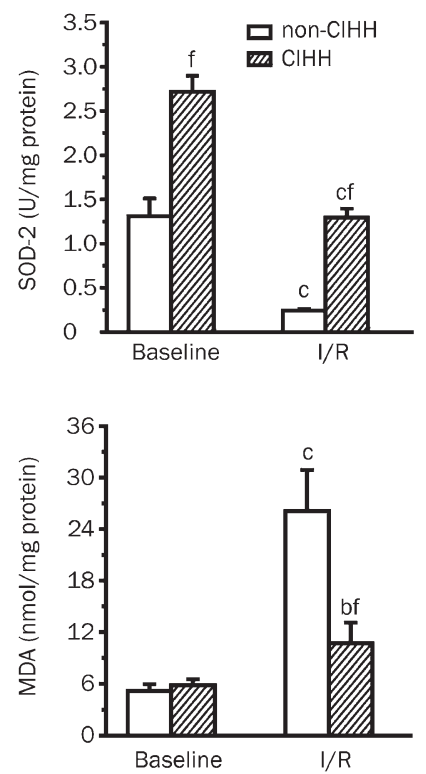

Figure 1. Effects of $\mathrm{ClHH}$ on antioxidant enzyme activity and MDA concentration in guinea pig hearts. SOD, superoxide dismutase; CAT, catalase; GPX, glutathione peroxidase; MDA, malondialdehyde; non$\mathrm{ClHH}$, control group; $\mathrm{ClHH}$, chronic intermittent hypobaric hypoxia group; baseline, pre-ischemia; I/R, $60 \mathrm{~min}$ after reperfusion. $n=6$. Values represent the means \pm SEM. ${ }^{\circ} P<0.01$ $v$ s corresponding baseline values; ${ }^{\mathrm{f}} \mathrm{P}<0.01$ vs the corresponding non$\mathrm{ClHH}$ group.

decreases in CF, LVPSP, $\pm \mathrm{d} p / \mathrm{d} t_{\max }$ and PRP and an increase in LVEDP were observed $(P<0.05$ or 0.01$)$. Compared with the CON group, $C F, \pm d p / d t_{\max }$ and PRP were higher and LVEDP was lower in $\mathrm{CIHH}$ treated rats $(P<0.05$ or 0.01$)$, suggesting that $\mathrm{CIHH}$ possesses significant protective effects on $\mathrm{H}_{2} \mathrm{O}_{2}$ induced contractile dysfunction. A similar improvement was also observed in $\mathrm{H}_{2} \mathrm{O}_{2}$-perfused non-CIHH hearts pretreated with CAT $(100 \mathrm{U} / \mathrm{mL})(P<0.05$ or 0.01$)$. Administration of ATZ also completely abolished the protective effect of $\mathrm{CIHH}$ on cardiac function $(P<0.05$ or 0.01$)$, but not before treatment with $\mathrm{H}_{2} \mathrm{O}_{2}$. Furthermore, ATZ had no effect on hearts in the non-CIHH group before or after $\mathrm{H}_{2} \mathrm{O}_{2}$ treatment. Pretreatment with $\mathrm{CIHH}$ did not change any cardiac function parameters before $\mathrm{H}_{2} \mathrm{O}_{2}$ perfusion, except for $\mathrm{CF}$, which was increased by
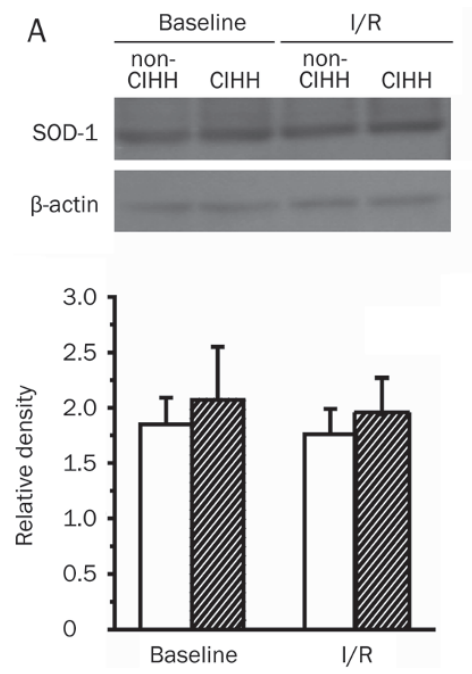
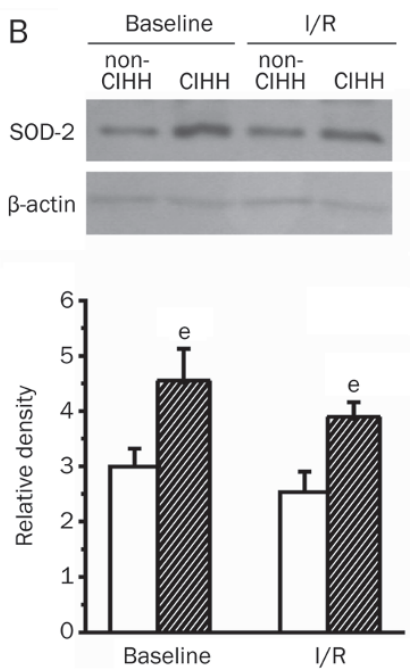
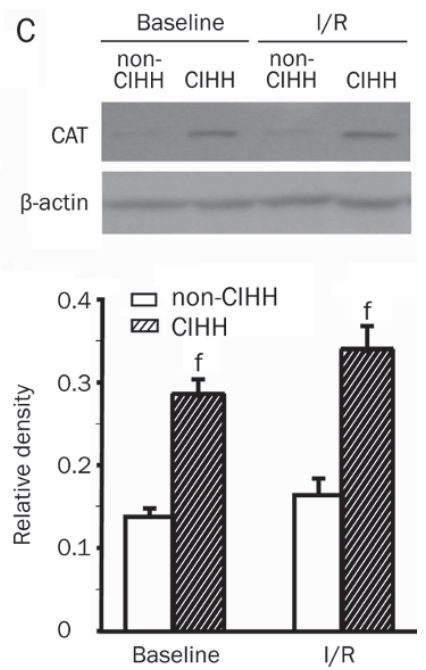

Figure 2. Effects of $\mathrm{CIHH}$ on the protein expression of SOD-1, SOD-2, and CAT in the left ventricle. SOD, superoxide dismutase; CAT, catalase. Top: representative lanes of a Western blot for SOD-1 (A), SOD-2 (B), or CAT (C). Bottom: densitometric analysis of SOD-1, SOD-2, and CAT bands normalized to $\beta$-actin. non- $\mathrm{ClHH}$, control group; $\mathrm{ClHH}$, chronic intermittent hypobaric hypoxia group; baseline, pre-ischemia; $1 / \mathrm{R}, 60 \mathrm{~min}$ after reperfusion. $n=5$. Values represent the means \pm SEM. ${ }^{e} P<0.05,{ }^{f} P<0.01$ vs the corresponding non-ClHH group. 
Table 3. Effects of $\mathrm{ClHH}$ on $\mathrm{H}_{2} \mathrm{O}_{2}$-induced changes in cardiac performance. $n=7$. Values are means $\pm \mathrm{SEM}$. ${ }^{\mathrm{b}} P<0.05$, ${ }^{\mathrm{c}} P<0.01$ vs corresponding baseline perfusion; ${ }^{\mathrm{P}} \mathrm{P}<0.05,{ }^{\mathrm{f}} \mathrm{P}<0.01$ vs corresponding of $\mathrm{CON}$; ${ }^{\mathrm{h}} \mathrm{P}<0.05,{ }^{\mathrm{i}} \mathrm{P}<0.01$ vs corresponding of $\mathrm{ClHH}$.

\begin{tabular}{|c|c|c|c|c|c|}
\hline & $\mathrm{CON}$ & $\mathrm{CON}+\mathrm{CAT}$ & $\mathrm{CON}+\mathrm{ATZ}$ & $\mathrm{ClHH}$ & $\mathrm{ClHH}+\mathrm{ATZ}$ \\
\hline \multicolumn{6}{|l|}{ Baseline } \\
\hline $\mathrm{CF}(\mathrm{mL} / \mathrm{min})$ & $22.3 \pm 1.4$ & $21.9 \pm 1.1$ & $24.1 \pm 2.2$ & $27.9 \pm 1.6^{\mathrm{e}}$ & $28.0 \pm 1.7^{\mathrm{e}}$ \\
\hline LVPSP (mmHg) & $92.5 \pm 7.2$ & $95.7 \pm 3.5$ & $102.0 \pm 5.8$ & $91.6 \pm 9.8$ & $100.8 \pm 8.0$ \\
\hline LVEDP (mmHg) & $5.1 \pm 1.4$ & $8.4 \pm 1.0$ & $7.0 \pm 1.3$ & $6.3 \pm 1.3$ & $7.8 \pm 1.0$ \\
\hline HR (beat/min) & $257 \pm 20$ & $261 \pm 18$ & $246 \pm 19$ & $255 \pm 15$ & $260 \pm 18$ \\
\hline $\operatorname{PRP}\left(10^{3} \mathrm{mmHg} / \mathrm{min}\right)$ & $22.5 \pm 1.9$ & $22.8 \pm 2.4$ & $23.4 \pm 3.1$ & $21.8 \pm 1.7$ & $24.2 \pm 2.0$ \\
\hline \multicolumn{6}{|l|}{$\mathrm{H}_{2} \mathrm{O}_{2}$} \\
\hline $\mathrm{CF}(\mathrm{mL} / \mathrm{min})$ & $5.7 \pm 0.5^{c}$ & $13.1 \pm 0.6^{c f}$ & $5.3 \pm 0.7^{c}$ & $14.7 \pm 1.1^{\mathrm{cf}}$ & $6.8 \pm 0.8^{\mathrm{ci}}$ \\
\hline LVPSP (mmHg) & $58.0 \pm 4.6^{c}$ & $70.6 \pm 4.0^{b}$ & $69.4 \pm 3.3^{c}$ & $65.6 \pm 6.2^{b}$ & $72.4 \pm 4.0^{b}$ \\
\hline LVEDP (mmHg) & $49.0 \pm 5.6^{c}$ & $28.6 \pm 4.8^{\text {be }}$ & $56.6 \pm 7.5^{c}$ & $25.6 \pm 5.8^{\text {be }}$ & $56.4 \pm 4.2^{\mathrm{ch}}$ \\
\hline $\operatorname{PRP}\left(10^{3} \mathrm{mmHg} / \mathrm{min}\right)$ & $2.3 \pm 0.5^{c}$ & $10.8 \pm 0.9^{c f}$ & $3.1 \pm 0.6^{c}$ & $10.1 \pm 1.0^{\text {cf }}$ & $4.1 \pm 0.6^{\mathrm{ci}}$ \\
\hline
\end{tabular}

CF, coronary flow; LVPSP, left ventricular peak systolic pressure; LVEDP, left ventricular end-diastolic pressure; HR, heart rate; $\pm d p / d t_{\text {max }}$, peak rate of pressure developed. PRP, pressure-rate product. CON, control hearts; CAT, catalase; ATZ, aminotriazole; CON+CAT, CAT treatment was started 10 min before $\mathrm{H}_{2} \mathrm{O}_{2}$ perfusion and continued throughout the $\mathrm{H}_{2} \mathrm{O}_{2}$ perfusion period in control hearts; $\mathrm{ClHH}$, chronic intermittent hypobaric hypoxia; CON+ATZ, control guinea pigs pretreated with ATZ $(1.0 \mathrm{~g} / \mathrm{kg})$ one hour before isolation of heart. $\mathrm{ClHH}+\mathrm{ATZ}$, ClHH guinea pigs pretreated with ATZ $(1.0 \mathrm{~g} / \mathrm{kg})$ one hour before isolation of heart.

CIHH and was not abolished by ATZ.

\section{Effects of $\mathrm{ClHH}$ on oxidative stress induced by $\mathrm{H}_{2} \mathrm{O}_{2}$ in single} cardiac myocytes

The fluorescent intensity was considerably higher and the staining was strikingly stronger in CON1 cardiac myocytes treated with $1 \mathrm{mmol} / \mathrm{L} \mathrm{H}_{2} \mathrm{O}_{2}$ for $10 \mathrm{~min}$. These results suggested an elevated level of ROS, which was significantly attenuated by CAT $(100 \mathrm{U} / \mathrm{mL})(P<0.01)$ (Figure 3$)$. The fluorescent intensity in $\mathrm{CIHH} 1$ cardiac myocytes was significantly lower than that of CON1 cardiac myocytes, and pretreatment with ATZ significantly increased the fluorescent intensity in CIHH1 cardiac myocytes $(P<0.01)$.

\section{Discussion}

We have shown that, although cardiac hypertrophy may not occur in the right and left ventricles, the adaptation of guinea pigs to $\mathrm{CIHH}$ significantly increased the cardiac tolerance to $\mathrm{I} / \mathrm{R}$ and $\mathrm{H}_{2} \mathrm{O}_{2}$ injury. We observed an improved recovery of contractile function, increased CF and a reduced level of ROS in cardiomyocytes, indicating that $\mathrm{CIHH}$ has a cardioprotective effect on isolated hearts subjected to I/ $\mathrm{R}$ and $\mathrm{H}_{2} \mathrm{O}_{2}$ injury and on isolated cardiomyocytes subjected to $\mathrm{H}_{2} \mathrm{O}_{2}$ injury. These results are consistent with studies showing the cardioprotection of $\mathrm{CIHH}$ in dogs and rats ${ }^{[5,9]}$, demonstrating that $\mathrm{CIHH}$ also has a protective effect on the hearts of guinea pigs, which are resistant to hypoxia and I/R injury. These results suggest that $\mathrm{CIHH}$ cardiac protection universally exists in ani- mals.

It is known that myocardial I/ $\mathrm{R}$ induces an injurious cascade of $\operatorname{ROS}^{[27]}$. In our study, CIHH was able to markedly promote the recovery of guinea pig cardiac function from a $30 \mathrm{~min}$ ischemic episode followed by $60 \mathrm{~min}$ reperfusion, suggesting the effect of antioxidant enzymes in the cardioprotection of $\mathrm{CIHH}$ in $\mathrm{I} / \mathrm{R}$ injury. Hydrogen peroxide is an important product of oxidative stress that could reach 1 to $2 \mathrm{mmol} / \mathrm{L}$ in the microenvironment during I/ $\mathrm{R}$ injury ${ }^{[28]}$. Oxidative stress can therefore be induced by direct perfusion of $\mathrm{H}_{2} \mathrm{O}_{2}$. In the present study, we perfused the isolated hearts and single cardiomyocytes of guinea pigs with $\mathrm{H}_{2} \mathrm{O}_{2}$ to mimic I/R injury induced by ROS. We found that $\mathrm{CIHH}$ promoted the recovery of heart function and reduced the elevated level of ROS in cardiomyocytes, which further indicated that antioxidant enzymes had a key role in the cardioprotection of $\mathrm{CIHH}$ against I/ R injury. When the hearts were pretreated with the CAT inhibitor ATZ, we observed that the cardioprotection offered by $\mathrm{CIHH}$ was abolished in either myocardial tissue or single cardiomyocytes subjected to I/ $\mathrm{R}$ or $\mathrm{H}_{2} \mathrm{O}_{2}$ injury. These findings are consistent with previous studies showing the administration of CAT inhibitors attenuated ischemic tolerance induced by hyperbaric oxygen ${ }^{[29]}$. Superoxide dismutase only converts $\mathrm{O}_{2}^{-}$generated in enzymatic reactions to $\mathrm{H}_{2} \mathrm{O}_{2}$, which is still harmful to tissue. Hydrogen peroxide is then converted to $\mathrm{H}_{2} \mathrm{O}$ by CAT or GPX; therefore, inhibition of CAT may also partly eliminate the action of SOD. When we pretreated the hearts and single cardiomyocytes subjected to I/ $\mathrm{R}$ or $\mathrm{H}_{2} \mathrm{O}_{2}$ injury from non- 
A
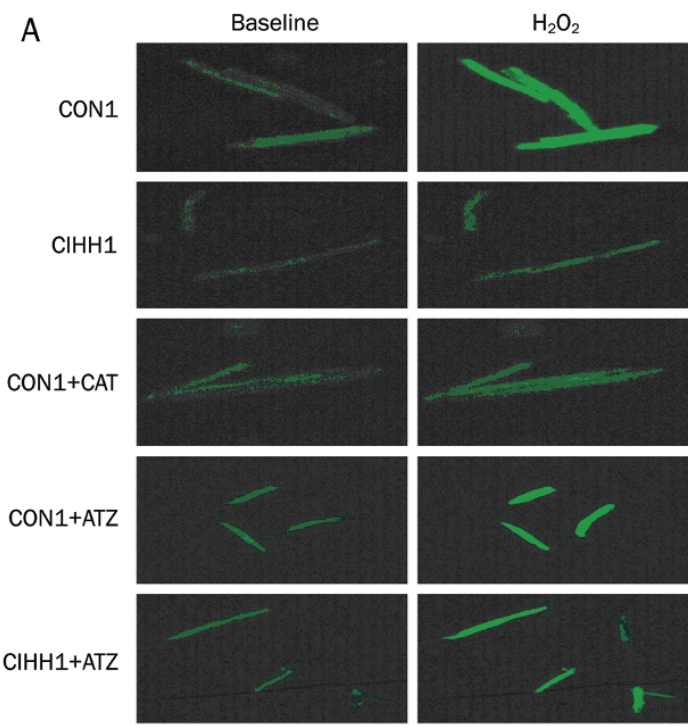

B

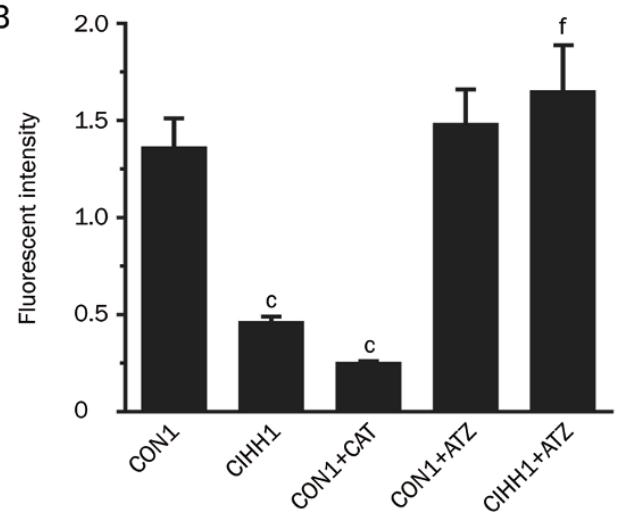

Figure 3. Effects of $\mathrm{ClHH}$ on $\mathrm{H}_{2} \mathrm{O}_{2}$-induced oxidative stress in isolated cardiac myocytes. CAT, catalase; ATZ, aminotriazole; CON1, non-CIHH group; CON1+CAT, CON1+CAT group; (3) CON1+ATZ, CON1+ATZ group; CIHH1, $\mathrm{ClHH}$ group; $\mathrm{ClHH} 1+\mathrm{ATZ}, \mathrm{ClHH} 1+\mathrm{ATZ}$ group. Myocytes were subjected to $\mathrm{H}_{2} \mathrm{O}_{2}$-induced injury using a protocol of 10 min baseline perfusion, followed by 10 min of $\mathrm{H}_{2} \mathrm{O}_{2}$ treatment. The myocytes in the CON1+CAT group were treated with CAT $(100 \mathrm{U} / \mathrm{mL})$ for $5 \mathrm{~min}$ before and $10 \mathrm{~min}$ during $\mathrm{H}_{2} \mathrm{O}_{2}$ treatment. Aminotriazole was administered intraperitoneally to the guinea pig $1 \mathrm{~h}$ before isolation of the heart in the CON1+ATZ and $\mathrm{ClHH} 1+\mathrm{ATZ}$ groups. (A) Fluorescent intensity changes in cardiac myocytes exposed to $\mathrm{H}_{2} \mathrm{O}_{2}$ (10 min). (B) The bar graph shows the fluorescent intensity that represents the ratio of $\left(\mathrm{FI}^{-} \mathrm{FI}_{0}\right) / \mathrm{FI}_{0} . \quad n=18$, from 3-4 different hearts. Values represent the means \pm SEM. ${ }^{c} P<0.01$ vs the CON1 group; ${ }^{\mathrm{f}} \mathrm{P}<0.01$ vs the $\mathrm{ClHH} 1$ group.

CIHH guinea pigs with the antioxidant enzymes SOD and/ or CAT, similar cardioprotection to $\mathrm{CIHH}$ adaptation was also observed. These data further confirm that, although the mechanism of the protective role is not precisely understood, a key part is played by antioxidant enzymes. It is important to note that we observed the increases in activity and protein expression of major antioxidant enzymes SOD-2 and CAT in the $\mathrm{CIHH}$ guinea pig myocardial tissue. Although the activity of these antioxidant enzymes decreased after myocardial I/R, a significantly higher activity of SOD-2 and CAT and a lower expression of MDA were observed in the $\mathrm{CIHH}$ group than those in the non-CIHH group. Taken together, our results strongly support the suggestion that antioxidant enzymes are involved in the cardioprotection of $\mathrm{CIHH}$ against I/ $\mathrm{R}$ insult. These results are consistent with previous findings showing that administration or overexpression of antioxidant enzymes can improve the recovery of the heart contractile function from $\mathrm{I} / \mathrm{R}$ injury ${ }^{[30-32]}$, indicating that CAT has an important role in cardiac protection against I/ $\mathrm{R}$ insult even though the its activity in the myocardium is low $^{[33]}$. Some studies ${ }^{[16,17,34]}$, however, suggest a close correlation between the increase in antioxidant enzyme activity and the cardioprotection induced by various ischemic and non-ischemic preconditioning methods. These methods have the characteristic of repetitive cycles of hypoxia and reoxygenation or ischemia and reperfusion, like CIHH. A previous report also found that intermittent hypoxia mimicking obstructive sleep apnea changed the susceptibility of the heart to oxidative stress, partly by the alteration of thioredoxin, but not SOD or CAT ${ }^{[35]}$. By contrast, some studies were unable to demonstrate the protective effects of antioxidant therapy or the use of some endogenous antioxidant enzymes against I/ $\mathrm{R}$ injury ${ }^{[36,37]}$. Koler et al reported that antioxidant enzymes in $\mathrm{CIHH}$ rats were not significantly changed ${ }^{[19]}$. Although some studies contradict our findings, our results strongly suggest that antioxidant enzymes may be critical for the cardioprotective effect against oxidative stress under some pathological conditions. Moreover, our results suggest that the induction and activation of SOD-2 and CAT could be the underlying mechanism of the cardioprotective effects associated with $\mathrm{CIHH}$.

ROS contributed to I/R injury and appeared to play the part of activator in processes in which $\mathrm{CIHH}$ upregulated the antioxidant enzymes, which may be a double-edged sword. Furthermore, ROS has been shown to be a second messenger for the induction of antioxidant enzymes in both prokaryotes and eukaryotes $^{[33]}$. During adaptation to $\mathrm{CIHH}$, repetitive cycles of hypoxia and reoxygenation (sub-lethal stresses) may lead to the production of ROS in the hypoxic myocardium, the latter triggering a cascade of events that lead to increased antioxidant enzyme activity. It has been reported that in prokaryotes, ROS modifies the protein structure of the transcription factor oxyR to an activated form, which induces the expression of the CAT gene ${ }^{[38,39]}$. These findings indicate that the ROS produced in myocardial tissue during sub-lethal stress may serve as a signal transduction pathway ${ }^{[33]}$ that forms a positive feedback loop consisting of ROS, transcriptional factors and cytokines and even a sequence of signaling events linking ROS, PKC- $\delta$, and mitoK $_{\mathrm{ATP}}$ channels ${ }^{[40]}$. Because mitochondria are particularly susceptible to oxidative damage from ROS, and because SOD-2 is located in mitochondria ${ }^{[40]}$, mitochondrial SOD-2 is more likely to be induced than cytosolic SOD-1. This not only indicates that the induction of SOD-2 in CIHH may have a critical role in the acquisition of CIHH against I/ R injury, such as in the delayed preconditioning ${ }^{[34]}$, but also explains why CIHH only increased the activity and protein expression 
of SOD-2 and not SOD-1. In addition to SOD-1, no significant change in GPX activity was observed in CIHH hearts in our experiment. Similar to our results, others have shown an increase in the activity of CAT and SOD in spinal cord tissue without affecting GPX activity ${ }^{[2]}$. These findings suggest that the relationship of GPX with ischemic tolerance is yet to be elucidated.

The present study showed that the baseline and recovery of $\mathrm{CF}$ after ischemia were higher in $\mathrm{CIHH}$ hearts compared with non-CIHH hearts, which is consistent with findings that capillary density and $\mathrm{CF}$ are higher in $\mathrm{CIHH}$ hearts ${ }^{[7]}$. These data suggest that the increase of $\mathrm{CF}$ is one possible mechanism for the protection conferred by $\mathrm{CIHH}$. In addition, other studies have found that the burst of vascular ROS production following I/ R can lead to dysfunction of coronary microvessels to reduce $C F^{[24,41]}$. These results are consistent with our findings showing that ATZ only abolished the recovery of cardiac function involving $\mathrm{CF}$ after I/ $\mathrm{R}$ or $\mathrm{H}_{2} \mathrm{O}_{2}$ perfusion, and did not affect the baseline values of cardiac function in $\mathrm{CIHH}$ hearts or of any parameters of cardiac function in non-CIHH hearts. This indicates that ATZ exerted its antagonistic role only in the presence of higher levels of CAT and oxidative stress, which may be due to the lower doses of ATZ that we used and the lower level of CAT in myocardium ${ }^{[33]}$. Previous studies have shown that a similar dose of ATZ did not deteriorate spinal cord ischemia or myocardial infarction in control rats ${ }^{[29,42]}$.

In previous studies, antioxidant capacity was only detected in ventricular tissue ${ }^{[4,17]}$. Here, the DCFH-DA method was used to detect the levels of intracellular ROS. Because the single cardiomyocyte does not contain neutrophils, endothelial cells or other potential sources of oxidants, our study directly demonstrates that the cardiomyocytes from $\mathrm{CIHH}$ hearts have an enhanced antioxidant capacity to scavenge ROS.

Injury that is induced by $I / R$ is an inevitable complication that depresses cardiac function and expands myocardial infarction. Although some studies have demonstrated adverse effects or controversial results of intermittent hypoxia ${ }^{[35]}$, the present findings imply that $\mathrm{CIHH}$ could be useful in the clinical setting for the prevention of $I / R$ injury in ischemic diseases. Moreover, the antioxidant supplementation in I/R injury may also have beneficial consequences.

In conclusion, the present study shows that $\mathrm{CIHH}$ upregulates the activity and protein expression of the antioxidant enzymes CAT and SOD-2, thereby leading to an increase in antioxidant capacity. This may play an important part in the cardioprotection of $\mathrm{CIHH}$ against I/ $\mathrm{R}$ injury in the guinea pig.

\section{Acknowledgements}

This project was supported by the Natural Science Foundation of Hebei Province of China (№ 301360).

\section{Author contribution}

Hui-cai GUO and Yong-li WANG designed the study; Huicai GUO and Zhe ZHANG performed the research; Li-nan ZHANG, Chen XIONG, Chen FENG, Qian LIU, Xu LIU, and Xiao-lu SHI contributed new analytical reagents and tools;
Hui-cai GUO, Yong-li WANG, Li-nan ZHANG, Qian LIU, and Chen XIONG analyzed data; Yong-li WANG and Hui-cai GUO wrote the paper.

\section{References}

1 Zhuang J, Zhou ZN. Protective effects of intermittent hypoxic adaptation on myocardium and its mechanism. Biol Signals Recept 1999; 8: 316-22.

2 Zhang Y, Yang HT, Zhou ZN. Cardioprotection of intermittent hypoxia. Acta Physiol Sin 2007; 59: 601-13.

3 Zhang Y, Zhong N, Zhou ZN. Effects of intermittent hypoxia on action potential and contraction in non-ischemic and ischemic rat papillary muscle. Life Sci 2000; 67: 2465-71.

4 Zhang Y, Zhong N, Zhu HF, Zhou ZN. Antiarrhythmic and antioxidative effects of intermittent hypoxia exposure on rat myocardium. Acta Physiol Sin 2000; 52: 89-92.

5 Zong P, Setty S, Sun W, Martinez R, Tune JD, Ehrenburg IV, et al. Intermittent hypoxic training protects canine myocardium from infarction. Exp Biol Med (Maywood) 2004; 229: 806-12.

6 Zhong N, Zhang Y, Fang QZ, Zhou ZN. Intermittent hypoxia exposureinduced heat-shock protein 70 expression increases resistance of rat heart to ischemic injury. Acta Pharmacol Sin 2000; 21: 467-72.

7 Zhong N, Zhang Y, Zhu HF, Wang JC, Fang QZ, Zhou ZN. Myocardial capillary angiogenesis and coronary flow in ischemia tolerance rat by adaptation to intermittent high altitude hypoxia. Acta Pharmacol Sin 2002; 23: 305-10.

8 Ding HL, Zhu HF, Dong JW, Zhu WZ, Zhou ZN. Intermittent hypoxia protects the rat heart against ischemia/reperfusion injury by activating protein kinase C. Life Sci 2004; 75: 2587-603.

9 Zhu HF, Dong JW, Zhu WZ, Ding HL, Zhou ZN. ATP-dependent potassium channels involved in the cardiac protection induced by intermittent hypoxia against ischemia/reperfusion injury. Life Sci 2003; 73: $1275-87$.

10 Bansal P, Gupta SK, Ojha SK, Nandave M, Mittal R, Kumari S, et al. Cardioprotective effect of lycopene in the experimental model of myocardial ischemia-reperfusion injury. Mol Cell Biochem 2006; 289: $1-9$.

11 Makazan Z, Saini H K, Dhalla NS. Role of oxidative stress in alterations of mitochondrial function in ischemic-reperfused hearts. Am J Physiol Heart Circ Physiol 2007; 292: H1986-94.

12 Kourie Jl. Interaction of reactive oxygen species with ion transport mechanisms. Am J Physiol 1998; 275: C1-24.

13 Eigel BN, Gursahani H, Hadley RW. ROS are required for rapid reactivation of $\mathrm{Na}^{+} / \mathrm{Ca}^{2+}$ exchanger in hypoxic reoxygenated guinea pig ventricular myocytes. Am J Physiol Heart Circ Physiol 2004; 286: H955-63.

14 Yun YS, Lee YN. Production of superoxide dismutase by Deinococcus radiophilus. J Biochem Mol Biol 2003; 36: 282-7.

15 Chen CF, Tsai SY, Ma MC, Wu MS. Hypoxic preconditioning enhances renal superoxide dismutase levels in rats. J Physiol 2003; 552: 561-9.

16 Kim CH, Hong C, Chun YS, Kim GT, Park JW, Kim MS. Hyperbaric oxygenation pretreatment induces catalase and reduces infarct size in ischemic rat myocardium. Eur J Physiol 2001; 442: 519-25.

17 Zhu WZ, Dong JW, Ding HL, Yang HT, Zhou ZN. Postnatal development in intermittent hypoxia enhances resistance to myocardial ischemia/ reperfusion in male rats. Eur J Appl Physiol 2004; 91: 716-22.

18 Nakanishi K, Tajima F, Nakamura A, Yagura S, Ookawara T, Yamashita $\mathrm{H}$, et al. Effects of hypobaric hypoxia on antioxidant enzymes in rats. J Physiol 1995; 489: 869-76. 
19 Kolar F, Jezkova J, Balkova P, Breh J, Neckar J, Novak F, et al. Role of oxidative stress in PKC- upregulation and cardioprotection induced by chronic intermittent hypoxia. Am J Physiol Heart Circ Physiol 2007; 292: H224-30.

20 Turek Z, Ringnalda BE, Moran O, Kreuzer F. Oxygen transport in guinea pigs native to high altitude. Pflugers Arch 1980; 384: 109-15.

21 Rivera CM, Lebn VF, Huicho L, Monge CC. Ventilatory response to severe acute hypoxia in guinea pigs and rats with low hemoglobinoxygen affinity induced by phytic acid. Comp Biochem Physiol 1995; 112: 411-6.

22 Su SW, Wang YL, Li JX, Mei HS, Yin JX. Relationship between cardiotonic effects and inhibition on cardiac sarcolemmal $\mathrm{Na}^{+}, \mathrm{K}^{+}$-ATPase of strophanthidin at low concentrations. Acta Pharmacol Sin 2003; 24 : 1103-7.

23 Kirshenbaum LA, Singal PK. Increase in endogenous antioxidant enzymes protects hearts against reperfusion injury. Am J Physiol 1993; 265: H484-93.

24 Maczewski M, Duda M, Pawlak W, Beresewicz A. Endothelial protection from reperfusion injury by ischemic preconditioning and diazoxide involves a SOD-like anti $\mathrm{O}_{2}^{-}$mechanism. J Physiol Pharmacol 2004; 55: 537-50.

25 Zang Q, Maass DL, White J, Jureta W, Horton JW. Cardiac mitochondrial damage and loss of ROS defense after burn injury: the beneficial effects of antioxidant therapy. J Appl Physiol 2007; 102: 103-12.

26 Wang Y, Gao J, Mathias RT, Cohen IS, Sun X, Baldo GJ. alphaAdrenergic effects on $\mathrm{Na}^{+}-\mathrm{K}^{+}$pump current in guinea-pig ventricular myocytes. J Physi ol 1998; 509: 117-28.

27 Jun J, Savransky S, Nanayakkara A, Bevans S, Li J, Smith L, et al. Intermittent hypoxia has organ-specific effects on oxidative stress. Am J Physiol Regul Integr Comp Physiol 2008; 295: R1274-81.

28 Bychkov R, Pieper K, Ried C, Milosheva M, Bychkov E, Luft FC. Hydrogen peroxide, potassium currents, and membrane potential in human endothelial cells. Circulation 1999; 99: 1719-25.

29 Nie H, Xiong LZ, Lao N, Chen SY, Xu N, Zhu ZH. Hyperbaric oxygen preconditioning induces tolerance against spinal cord ischemia by upregulation of antioxidant enzymes in rabbits. J Cerebr Blood F Met 2006; 26: 666-74.

30 Sekili S, McCay PB, Li XY, Zughaib M, Sun JZ, Tang L. Direct evidence that the hydroxyl radical plays a pathogenetic role in myocardial "stunning" in the conscious dog and demonstration that stunning can be markedly attenuated without subsequent adverse effects. Circ Res
1993; 73: 705-23.

31 Woo YJ, Zhang JC, Vijayasarathy C, Zwacka RM, Englehardt JF, Gardner TJ. Recombinant adenovirus-mediated cardiac gene transfer of superoxide dismutase and catalase attenuates postischemic contractile dysfunction. Circulation 1998; 98: ॥255-60.

32 Ostadal P, Elmoselhi AB, Zdobnicka I, Lukas A, Elimban V, Dhalla NS. Role of oxidative stress in ischemia-reperfusion-induced changes in $\mathrm{Na}^{+}, \mathrm{K}^{+}$-ATPase isoform expression in rat heart. Antioxid Redox Sign 2004; 6: 914-23.

33 Marklund SL, Westman NG, Lundgren E, Roos G. Copper- and zinccontaining superoxide dismutase, manganese-containing superoxide dismutase, catalase, and glutathione peroxidase in normal and neoplastic human cell lines and normal human tissues. Cancer Res 1982; 42: 1955-61.

34 Hoshida S, Yamashita N, Otsu K, Hori M. The importance of manganese superoxide dismutase in delayed preconditioning: involvement of reactive oxygen species and cytokines. Cardiovasc Res 2002; 55: 495-505.

35 Park AM, Suzuki YJ. Effects of intermittent hypoxia on oxidative stress-induced myocardial damage in mice. J Appl Physiol 2007; 102: 1806-14.

36 Kaplan P, Matejovicova M, Herijgers P, Flameng W. Lack of the effect of superoxide dismutase and catalase on $\mathrm{Na}^{+}, \mathrm{K}^{+}$-ATPase activity in stunned rabbit hearts. Physiol Res 2008; 57: S61-6.

37 Jones SP, Hoffmeyer MR, Sharp BR, Ho YS, Lefer DJ. Role of intracellular antioxidant enzymes after in vivo myocardial ischemia and reperfusion. Am J Physiol 2003; 284: H277-82.

38 Storz G, Tartaglia LA. OxyR: a regulator of antioxidant genes. J Nutr 1992; 122: 627-30.

39 Storz G, Tartaglia LA, Ames BN. Transcriptional regulator of oxidative stress-inducible genes: direct activation by oxidation. Science 1990; 248: 189-94.

40 Budas GR, Churchill EN, Rosen DM. Cardioprotective mechanisms of PKC isozyme-selective activators and inhibitors in the treatment of ischemia-reperfusion injury. Pharmacol Res 2007; 55: 523-36.

41 Sukmawan R, Yada T, Toyota E, Neishi Y, Kume T, Shinozaki Y, et al. Edaravone preserves coronary microvascular endothelial function after ischemia/reperfusion on the beating canine heart in vivo. J Pharmacol Sci 2007; 104: 341-8.

42 Auyeung Y, Sievers RE, Weng D, Barbosa V, Wolfe CL. Catalase inhibition with 3-amino-1,2,4-triazole does not abolish infarct size reduction in heat-shocked rats. Circulation 1995; 92: 3318-22. 